\title{
Urban public space between fragmentation, control and conflict
}

\author{
Alfredo Mela
}

\begin{abstract}
The article is focused on the different tendencies affecting urban public space in contemporary cities. It is based on a reflexion on some emerging themes in the recent debate in urban studies, paying particular attention to the approaches that emphasize the fragmentation of public space and the presence of control strategies, highlighting the function of tecnologies and material elements of built environment. The main thesis of the article is that public space, far from having become marginal in a context where virtual relations have a growing importance, is a field in which various types of dialectical tensions operate. In particular, at the one hand, in different contexts it is possible to recognize the presence of a complex strategy of domestication and control of urban places, linked to a process of commodification and privatisation. On the other hand many types of opposing practices and movements are also present, that propose an alternative project of use. In this framework, public space is both a place of confrontation between opposing tendencies and a stake, on which future city models depend significantly.
\end{abstract}

\section{Introduction}

Public space is a crucial theme in the urban studies of this first part of the $21^{\text {st }}$ century for theoretical reasons and, at the same time, for its practical-political relevance. From a theoretical point of view, the transformations of public space and its crisis are often analysed as a key for the study of socio-spatial changes in post-industrial society and, in more general terms, as an interpretative factor of social relations in contemporaneity. From a political point of view, public areas of the city are examined as one of the arenas in which the contradictions and conflicts, typical of the current phase, are displayed; contradictions that take place at a macro-social level - for example between large renewal projects of urban centres and the needs of populations threatened with expulsion - as much as on the micro level, between practices of specific groups and social actors in daily life frameworks.

This article aims to focus, in fact, on this plural and often conflicting dimension of urban space, trying to show how - far from having become marginal in a society in which virtual interactions have a primary importance - it could be represented as a field in which various types of dialectical tensions operate, on which the power relations and lifestyles of contemporary societies significantly depend. In particular, on the one hand

Correspondence: alfredo.mela@polito.it

Politecnico di Torino, Torino, Italy

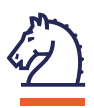

Springer

(c) 2014 Mela; licensee Springer. This is an Open Access article distributed under the terms of the Creative Commons Attribution

License (http://creativecommons.org/licenses/by/4.0), which permits unrestricted use, distribution, and reproduction in any

medium, provided the original work is properly credited. contemporary cities are affected by processes of control and normalization of citizens' behaviour; on the other hand they are witnessing the development of social practices aimed at countering the control and to propose alternative ways of use of public space. In paragraph 2 we take into account some interpretative lines in the debate of social sciences on the city, focussing on those which study tendencies of domestication and control of public places. Paragraph 3 examines the role of technology and the material dimension of built environment; in the $4^{\text {th }}$ we reflect on the practices and bottom up movements which represent a form of resistance and an alternative to the dominating strategies of urban governance. Finally, in the conclusion we highlight the characteristics of contemporary public space as a place where a complex set of conflicting practices take place and as a stake in the construction of new urban lifestyles.

\section{Public space, pacification and control}

A large part of the debate on public space in the contemporary city revolves around the analysis of crisis factors of public space, or rather the transformation trends of the post-industrial societies that bring a radical change in the functions of urban places, their meanings and symbolism, the practices that are carried out in them. We could say that this debate is structured on different levels. On the one hand, there are the reflections of a more 
abstract order, which examine the consequences on an urban scale of processes characterising contemporary societies on a global scale, such as the transformations of governance and urban policies (Mac Leod 2011), public sphere (Castells 2008); the processes of metropolisation, loss of city limits (Gillham 2002), increasing mobility, growth of digital connections and on line communication, and change of space and time structures (Smith 2003). On the other hand, there are contributions that analyse urban public spaces in specific contexts, as well as projects and practices that characterise them, often focussing on particular types of place, such as green areas and urban agriculture fields (Bergamaschi 2012), libraries (Given et al. 2003), town squares, shopping areas, pavements (Loukaitou-Sideris and Ehrenfeucht 2009), sports areas (Puig et al. 2006) and so on. In these cases, reflections often start with empirical analyses on individual cities or with comparative analysis between different contexts (Mazzette 2013) and attempt to link the results of fieldwork to the themes of international theoretical debate.

We could observe that often more abstract reflections tend to highlight crisis factors, emphasising the split between traditional models of public space, or even of industrial modernity models, and the current postmodern forms. Instead, in many cases the analyses that derive from empirical studies highlight at the same time the crisis and the persistent vitality of urban places they study, showing the evolution of practices deriving from the emergence of new actors or urban populations, or from innovative design trends, as well as the presence of new forms of social conflict linked to the city use.

In any case, there are themes of debate that represent a sort of bridge between theoretical and empirical studies. A central topic refers to the fragmentation of the urban public space, a phenomenon also connected with the privatisation trends the city (Kohn 2004). The analysis of these processes lends itself to an interpretation that starts from the macro-social level, as well as to an observation based on the urban micro-spaces. From a more general viewpoint, the segmentation and specialisation of the urban space is, at the same time, the spatial reflection of processes that regard the social and cultural sphere and which lead to the multiplication of groups and lifestyles - and the effects of capitalist and neoliberal policies, which lead to the reduction of the common goods sphere and the appropriation of them by the market.

In this perspective the analyses of David Harvey have a central place; this author, throughout his work, has always underlined both the central role of processes of urbanisation in capitalist accumulation, and the importance of urban struggles as a fundamental axis of the opposition to capitalism. In his more recent works, (especially Harvey 2010, 2012), he particularly insists on the structural character of "accumulation by dispossession", the mechanism of creative destruction through which the market takes possession of common goods. $\mathrm{He}$ also strongly emphasizes the urban origins of the crisis of the capitalistic model. Furthermore, he highlights that the great urban transformations of contemporary history (from that of Paris in the Second Empire, to the American suburbanisation of the second post-war period, up to the globalised processes of urbanisation of the last few decades) have always caused radical changes in lifestyles and in power relationships between social groups. In this regard, a distinctive characteristic of the current transformations is the multiplication of urban market niches, which "suffuses the contemporary urban experience with an aura of freedom of choice, provided you have the money" (Harvey 2010, p. 175).

We could say that this fragmentation of the market and consumption, in their various aspects, correspond to the subdivision of the city into spaces - or rather into spacetime frames - each of which takes on a peculiar character and aims at a particular target of consumers. The theming of the urban areas and the presence of a dialectic between inclusive and exclusive mechanisms is a consequence of these trends, favoured by the sprawling form of contemporary urbanisation. The metropolitan sprawl - which, after all, shows different patterns in each context - and the diffusion of urban poles also in extra-urban territory facilitates the physical separation between specialised fragments of public space aimed at different social or consumers groups.

This phenomenon, however, presents contrasting aspects and is not free of contradictions. On the one hand, it takes on the character of pacification and domestication of places. This is the dimension that focusses more on inclusion than exclusion, or rather, which stakes more on the attraction capacity of certain public spaces for specific users, in ways that mask the repulsion aspects for other potential users. To this end, the concept of "ambient power" proposed by Allen (2006) is interesting, highlighting how the creation of a specific atmosphere in particular urban places makes some practices easier and discourages others. It is not solely about a mise-en-scene professionally combining various types of sensorial stimulation, from the experience of walking (Degen and Gillian 2012) to the visual and olfactory (smellscapes: Henshaw 2013) passing through the creation of soundscapes (Atkinson 2007). It is especially important to favour a soft and domestic experience of these spaces leaving the processes of control and selection in the background, while remaining in any case constantly in operation. Shopping areas, be they malls or public roads destined to tourists and gentrifiers, are a paradigmatic example of this type of strategy based fundamentally on seduction.

On the other hand, though, are the strategies in which the function of public space control, instead of being left in the background, is clear and takes on a visibly exclusive character. Large, extraordinary events hosted by 
cities, such as the Olympics or other large sporting, political or religious events, are emblematic of these strategies that use complex surveillance assemblages (Boyle 2012). The aspect of seduction and beautification (Newton 2009) is also strongly highlighted in these situations: just think, for example, of the urban cosmetic strategies undertaken to hide the favelas in Rio de Janeiro in view of the 2014 World Cup and the 2016 Olympics, trying to commercialise a stereotyped and sweetened image of them (Steinbrink 2013). Nonetheless, just like the cases of Rio and London Olympic Games show, strategies to boost security in the city and to eliminate - or at least to hide - all possible activities in contrast with the city image they want diffuse are put in the full light, to reassure the public of sporting events and to guarantee profit for the investors. The case of mega-events, after all, is just one of the most visible aspects of a policy of growing control on the city and its spaces, leading some author to consider it a true process of urban militarisation (Graham 2010), justified as measures against terrorism, clandestine immigration or simply as a response to increasing worries for the safety of urban spaces. It is a process where many factors contribute, including the "ordinary" technologies of urban control and the diffusion of a media culture inspired by military violence and the development of an economy based on the industry of security (Graham 2012).

Seduction and control strategies operate in a synergic way and create evident effects on the form of urban public space. To recall a frequently used metaphor, these effects can be described as a process of capsularisation of metropolitan areas (De Cauter 2004): the city is fragmented into a multiplicity of closed or, in any case, controlled spaces, that defend the occupants from unwanted stimuli and which regulate their behaviour. Residential areas - in particular gated communities - and commercial ones, such as university campuses, leisure centres, tourist and cultural areas, represent "real" capsules which, in turn, interconnect with "virtual" ones that are always accessible through the internet and social networks. Daily life is carried out predominantly in capsules or along the channels of communication that join them: motorways, underground systems, metropolitan railways, cycle paths. Beyond this network are the marginal areas, in many contexts left, specially but not exclusively in Global South metropolises, to spontaneous forms of control and, often, dominated by criminal organisations, which means that these areas also become particular types of capsule. In this perspective, then, both capsules and channels of interconnection lose their image as "meeting places" and free access zones, an image which is traditionally linked to public spaces. They are privatised and lend themselves especially to mono-dimensional and individual use, paradoxically leaving a truly public function only to interstitial areas, which are not controlled by any public or private agencies.

\section{Technology and material dimension of the space}

The hypothesis of an integral capsularisation of the city could be criticised as a dystopic vision - implying a unidirectional evolution of urbanism that requires the destruction of the public space - without offering a way out. As we will see below, however, there are processes in contemporary cities that move in the opposite direction and configure public places as a space in which to build alternative projects for the city. In any case, the capsularisation hypothesis has the advantage of clearly indicating a risk that is linked to the increasingly capillary role of urban technologies and the various interfaces between "real" and "virtual" worlds.

This evokes a very important theme of the current debate regarding the public space and on the projects that regard it: the key-word, on which this debate is focussed, is the transformation of the city into a "smart" city. In recent years, the concept of smart city has had huge success not only in the academic field but also - and above all - in administrations and institutions of different level. Despite this, its definition remains open to multiple interpretations. The broadest definitions tend to use this concept as a general paradigm of a desirable future city, including many integrating dimensions: economy, mobility, environment, social relations, lifestyles, governance are all fields of application of the smartness philosophy (Chourabi et al. 2012). Moreover, this vision is based on the idea that the key to success of every possible urban policy or project is in the application of innovative technologies and, in particular, of ICTs. This idea is explicit, for example, in the proposed definition in a recent study promoted by the European Parliament, in which it is said that "a Smart City is a city seeking to address public issues via ICT- based solutions on the basis of a multi stakeholder, municipally based partnership" (European Parliament 2014, p. 17).

Concerning specifically public spaces, there are multiple applications that regard, for example, the transport system, tourist areas, commerce, museums and cultural activities. Furthermore, ICTs can ease use of all types of public space, favouring an increase in security, reducing road risks, controlling environmental parameters and so on. Taking into account this potential distribution, smart cities are often presented as the proposal of an inclusive city, whose public spaces are strongly interconnected and open to generalised use.

However, in a conspicuous part of literature and, above all, in the experiences presented as concrete applications of the smartness philosophy, there are often aspects that 
bring forth doubts on the effective inclusivity of smart cities (Santangelo et al. 2013).

Firstly, it can be noted that, beyond the rhetoric of integration and multidimensionality of the concept, in many cases not only is the accent placed almost exclusively on technology, but there is also the expectation that their development would lead to an opening of new markets. In this sense, therefore, we can suspect that there is a close relationship between smart cities and the policies aimed at the idea of an entrepreneurial city (Hollands 2008). It is because of this research into marketoriented technological solutions that we can then observe that not all urban spaces, nor all their users, are as likely to undergo innovative projects. Quite the contrary - the applications are more likely to be aimed first at areas of particular economic interest (for example, tourism, commerce, showbusiness, as well as stations, airports, gentrified central areas) and less likely to affect places in which the poorest part of the population live, unless - perhaps to increase control over them. If this were found to be the case, it would end up seconding, instead of contrasting, the fragmentation or even the capsularisation of public spaces, highlighting the imbalance between public environments that take on a smart look and those that maintain a "non-intelligent" character.

The attention in the technological dimension in its relationship with the city and public spaces does not only regard the smart city debate. More in general, as Saskia Sassen states, today we can observe an increasingly striking interconnection between "real" and "virtual" urban spaces and even a sort of interexchange between them: "much of what is liquefied and circulates in digital networks and is marked by hypermobility, actually remains physical and hence possibly urban in some of its components. At the same time, however, that which remains physical has been transformed by the fact that that is represented by highly liquid instruments that can circulate in global markets" (Sassen 2006, p.24).

It can be noted that the attention to digital technology in current debate is often linked to an increasingly wide discovery of the materiality of the city and its public spaces. This implies an increasing interest in the physical reality of the built environment and in the ways the non-human elements of public space (the "actants", to use Latour's 2005 concept) interact with the social actors' behaviour. In many recent contributions, the influence of the Actor Network Theory (ANT) has in fact led to sociological interpretations not limited to the human sphere but able to also include in their analysis actants playing an active role in social contexts. In this, Latour himself also contributed with his polemic against a representation of the objects anchored to the Cartesian conception of the res extensa as an inert material, on which only the res cogitans actively works. This old conception contrasts with the emerging idea that the material elements of built environment - be they technological devices (Crang and Graham 2007), architectures, urban furniture - can actively interact with human action, for example by regulating the use of a space, drawing the attention of people, concentrating and mixing the flows of actors and so on (Latour and Yaneva 2008). This idea must not be confused with the affirmation of determinism of space on human behaviours: rather, it intends to affirm an interaction characterised by a reciprocal influence of actors and actants and their interconnection that leads to forming complex networks.

The reference to the ANT and the attention to the role of material elements could help us to understand the forms in which different ways of using the territory are stabilised and established in close relation with specific settings in the built environment. This stabilisation, in many cases, may also be considered what is at stake in conflicts rising in public areas and may become the objective of explicit strategies of control and domestication (Kärrholm 2008). So, we need to underline the close relationship between the processes of gentrification and commercialisation, which take place in central areas of the city or in the regeneration of ex-industrial areas, and the pedestrianisation of some roads, the presence of security cameras, the creation of an urban setting that encourages people to spend time outside. We could, therefore, conclude that the attention to materiality and the activity of the built space helps us to better understand the many strategies of seduction and control, clarifying in which ways these strategies boast design that involves at the same time actors and actants, favouring reciprocal interactions and connecting them on the sensorial, functional and symbolic levels.

\section{Conflict and practices}

Until now, we have mainly highlighted the tendencies to the transformation of public urban places that come from above, or rather from strategies put in place by public or private institutions or, again, by public-private coalitions and partnerships, aimed at controlling the spaces in view of their economic valorisation and neutralising any practices that contrast with this goal. These strategies, however, are often at odds with the opposition of social actors who act in an organized way to counter them or, simply, depict alternatives for the organisation and use of urban public places through their practices and lifestyles.

Regarding these practices, it is good to note how they present a high level of heterogeneity and which - while opposing themselves to strategies of privatisation and control of urban spaces - may lead to different results. To schematise, we can identify two distinct axes, based on which it is possible to classify the bottom up practices 
which, overall, represent an alternative to top down strategies.

The first axis regards the grade of intentionality and structuring of said practices. On one extreme are the processes based on an alternative project of definition and use of public spaces. In this case, moreover, the practices are structured in actual projects of citizenship, which not only are expressed through behaviour but also propose explicit alternative models of public space (Tamayo 2006): these therefore give place to social movements or, in any case, to collective forms of expression. On the other extreme, there are processes that derive spontaneously from individual or group behaviour so they propose a non-conventional use of the public space, without defining proposals or projects for transformation. These may derive, for example, from the presence of "new populations" in urban space - like new immigrants or the young protagonists of the nightlife (Hael 2011; Mela 2014) - or from the diffusion of new lifestyles and behavioural patterns.

The second axis regards, on the other hand, the nature of the practices and activities with which these counter the strategies of privatisation and commercialisation of the city. On one hand, we can place those practices that fundamentally express a desire to participate in decisions regarding public space and its management: people acting in this way, therefore, consider (explicitly or implicitly) public space as common property that must be defended and conserved to keep it open to multiple kinds of use and types of users. Often these actors are willing to collaborate with public institutions, as long as these are on the same page and are open to citizens' participation.

On the other hand, we find the practices that have an essentially antagonistic meaning: some groups or sectors of the urban population are opposed to projects or policies carried on by public institutions. These actors refuse (explicitly or implicitly) each form of co-participation or dialogue with institutions or with differently characterised groups, emphasizing their identity and autonomy.

Figure 1 shows how the intersection of these axes ends up structuring a field of practices put into act by individuals or groups and subdivided this field into four quadrants.

In quadrant $\mathrm{A}$, therefore, are the collective movements of organised citizens and civil society associations, that aim to have more weight in planning and managing urban public space. They act in a participatory way while also expressing their disagreement when it is useful for the success of their action. In quadrant B, we find alternative uses of public space which display merely an active and intense use of it, in contexts in which - to repeat Amin's concepts (2008) - the ethics of the situation, influenced by the physical configuration of places in a context of throwntogetherness (Massey 2005), favour practices that ensure a variety of uses and accept diversity. In quadrant $C$, there are different types of antagonist organised movements that use public space as a place to conflict with power, in forms that consider the control of specific spaces as a decisive action in practical and symbolic terms. Finally, in D, are non-organised behavioural forms which, nonetheless, have the effect of favouring the control of public spaces by marginal groups or by actors with alternative lifestyles.

It is obvious, after all, that this classification of the practices must not be intended as a rigid division in clearly distinct categories. Often the phenomena that we truly observe in urban public spaces are mixed, and we see that even the same phenomenon can take on different connotations in time and space, depending on context variables and on its evolution for internal dynamics or in reply to external interventions.

\section{Public space as a place of dialectic tensions}

The reflections in this article have highlighted, above all, the great complexity of the tensions to which public

participation

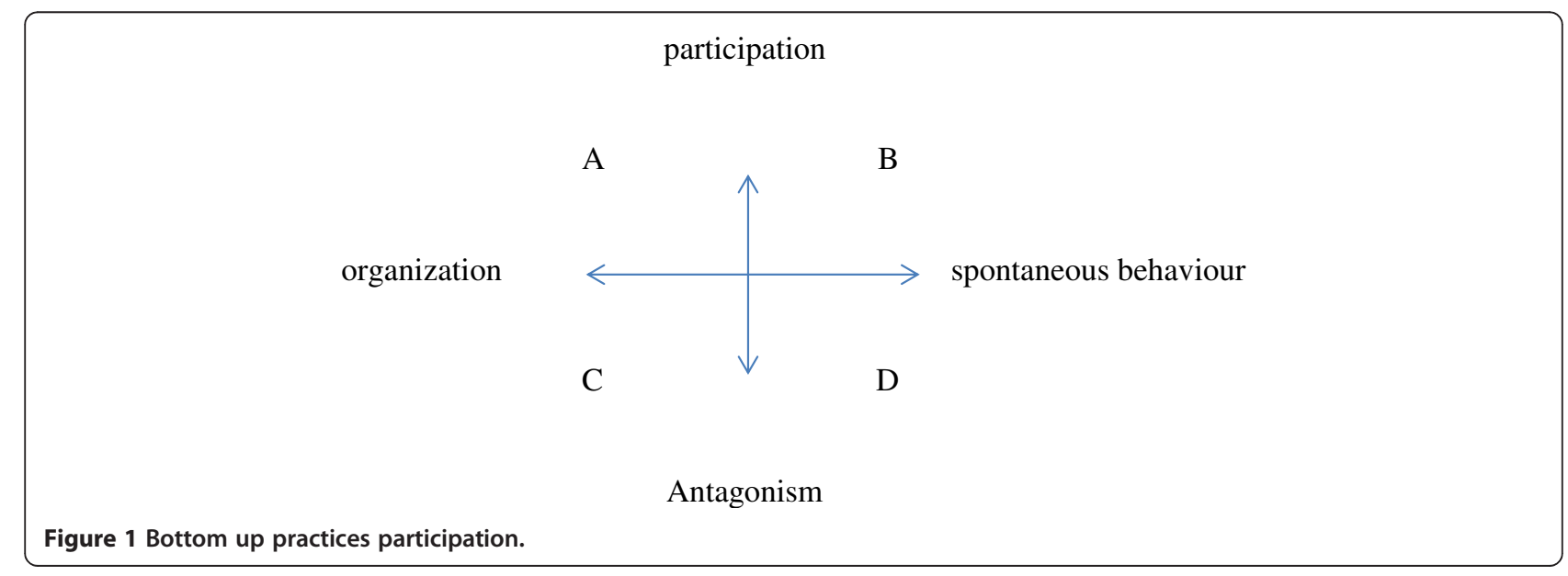


spaces in contemporary cities are subject and the presence of opposing strategies and practices aimed to their organisation and use.

In summary, we can say that today, in most urban contexts, we are witnessing the intensification of strategies that imply the fragmentation of the public space that is, the increase of zoning practices that do not correspond to a public plan but more to demands of the market -urban sprawl and the commercialisation of places (Borja 2003). These strategies present two different - seemingly opposing - versions that are, in reality, complementary: one that aims at seducing the various types of consumers and tries to domesticate urban places, and one that is expressed through explicit control and exclusion. The first version, the soft one, creates comfortable environments that are configured like capsules adapted to specific forms of consumption; the second, the hard one, guarantees a security of use by expelling every form of behaviour and, even, the physical presence of social groups incompatible with the needs of private economy and political power. Technology often has an essential role in both versions - beyond the rhetoric that exalts their smartness - as do the physical elements of the built space, highlighting their active role in the interaction with the behaviours of social actors.

Strategies of this nature have a top-down character, or rather they are the result of a process of governance of the city and its public spaces that starts from a network of public and private actors. Nevertheless, these are effective only when they actually find a positive response from wide social groups or are able to prevail over opposing tendencies. Therefore this effectiveness is not always guaranteed; in fact, even the public space of contemporary cities - though in a different form than in the past - is a place of resistance against the dominating strategies, which are bottom up. These opposing processes are not always well organised, nor do they necessarily express conscious alternatives: sometimes they occur purely as practices in public spaces that actually conflict with those proposed by the dominant models of governance. In different situations they may express a genuine aspiration to an inclusive participation or themselves act as forms of occupation and control of the urban spaces with exclusionary effects in relation to other actors or other practices.

In any case, the presence of these alternatives, even with the ambivalence that distinguishes them, highlight the fact that urban public space is still at the centre of dialectic tensions. We cannot predict how these tensions will end, though they are of great importance in creating relationships of power among social groups and in defining the very meaning of cohabiting in the city. Furthermore, this shows how the form of urban space, in its physical and symbolic dimension, is not only a question of aesthetic or functional choices, but is a decisive factor in the dialectics between individual and collective social actors and plays an important role in the prevalence of inclusive or exclusive models of social relations.

\section{Competing interests}

The author declares that he has no competing interests.

Received: 13 November 2014 Accepted: 13 November 2014

Published online: 12 December 2014

\section{References}

Allen J (2006) Ambient power: Berlin's Potsdamer Platz and the seductive logic of public spaces. Urban Stud 43(2):441-455

Amin A (2008) Collective culture and urban public space. City 12(1):5-24

Atkinson R (2007) Ecology of sound: the sonic order of urban space. Urban Stud 44(10):1905-1917

Bergamaschi M (2012) Coltivare in città. Orti e giardini condivisi. Sociol Urbana e Rural 98:7-11

Borja J (2003) La ciudad conquistada. Alianza Editorial, Madrid

Boyle P (2012) Securing the Olympic Games: Exemplifications of Global Governance. In: Lenskyj HJ, Wagg S (eds) The Palgrave Handbook of Olympic Studies. Palgrave MacMillan, Houndmills, Basingstoke

Castells M (2008) The New Public Sphere: Global Civil Society, Communication Networks, and Global Governance. Ann Am Acad Pol Soc Sci 2008(616):78-93

Chourabi H, Gil-Garcia JR, Mellouli S, Nahon K, Nam T, Pardo TA, Scholl HJ, Walker S (2012) Understanding Smart Cities: An Integrative Framework, Proceedings of the 45 th Hawaii International Conference on System Sciences. IEEE Computer Society, Maui, pp 2289-2297

Crang M, Graham S (2007) Sentient cities: ambient intelligence and the politics of urban space. Inf Commun Soc 10(6):789-817

De Cauter L (2004) Capsular Civilization: On the City in an Age of Fear. Nai Publishers, Rotterdam

Degen MM, Gillian R (2012) The sensory experiencing of urban design: the role of walking and perceptual memory. Urban Stud 49(15):3271-3287

European Parliament (2014) Mapping Smart Cities in the EU., http://www. europarl.europa.eu/RegData/etudes/etudes/join/2014/507480/IPOL-ITRE_ET\% 282014\%29507480_EN.pdf

Gillham O (2002) The Limitless City. A Primer on the Urban Sprawl Debate. Island Press, Washington, D.C

Given LM, Gloria J, Leckie GJ (2003) "Sweeping" the library: mapping the social activity space of the public library. Libr Inf Sci Res 25(2003):365-385

Graham S (2010) Cities under Siege. The New Military Urbanism, Verso, London

Graham S (2012) When life itself is war: on the urbanization of military and security doctrine. Int J Urban Reg Res 36(1):136-155

Hael $L$ (2011) Dilemmas of the nightlife fix: post-industrialization and the gentrification of nightlife in New York City. Urban Stud 48(6):3449-3465

Harvey D (2010) The Enigma of Capital and the Crises of Capitalism. Profile Books, London

Harvey D (2012) Rebel Cities. From the Right to the City to the Urban Revolution. Verso, London-New York

Henshaw V (2013) Smellscapes. Understanding and Designing City Smell Environments. Routledge, London-New York

Hollands RG (2008) Will the real smart city please stand up? Intelligent, progressive or entrepreneurial? City 12(3):303-320

Kärrholm M (2008) The Territorialization of a Pedestrian Precinct in Malmö: Materialities in the Commercialisation of Public Space". Urban Stud 9 (45):1903-1924

Kohn M (2004) Brave New Neighborhoods. The Privatization of Public Space. Routledge, London-New York

Latour B (2005) Reassembling the Social: An Introduction to Actor Network Theory. Oxford University Press, Oxford

Latour B, Yaneva A (2008) Give me a Gun and I will Make All Buildings Move. In: Geiser R (ed) Explorations in Architecture: Teaching, Design, Research. Birkhäuser, Basel, pp 80-89

Loukaitou-Sideris A, Ehrenfeucht R (2009) Sidewalks. Conflict and Negotiation over Public Space. The M.I.T. Press, Cambridge (Ma) - London 
Mac Leod G (2011) Urban politics reconsidered: growth machine to postdemocratic city? Urban Stud 48(12):2629-2660

Massey D (2005) For Space. Sage, London

Mazzette A (ed) (2013) Pratiche sociali di città pubblica. Laterza, Roma-Bari

Mela A (ed) (2014) La città con-divisa. Angeli, Milano

Newton C (2009) The reverse side of the medal: about the 2010 World Cup and the beautification of the N2 in Cape Town. Urban Forum 20(1):93-108

Puig N, Vilanova A, Camino X, Maza G, Pasarello M, Juan D, Tarragó R (2006) Los espacios públicos urbanos y el deporte como generadores de redes sociales. El caso de la ciudad de Barcelona. Apunts Educ Fís y Deportes 84:76-87

Santangelo M, Aru S, Pollio A (eds) (2013) Smart City. Ibridazioni, innovazioni e inerzie nelle città contemporanee. Carocci, Roma

Sassen S (2006) Public interventions: the shifting meaning of the urban condition. Open 11:18-27

Smith RG (2003) World city topologies. Prog Human Geogr 27(5):561-582

Steinbrink M (2013) Festifavelisation: mega-events, slums and strategic city-staging - the example of Rio de Janeiro. Die Erde 144(2):129-145

Tamayo S (2006) Espacios de ciudadanía, espacios de conflicto. Sociológica 21(61):11-40

doi:10.1186/s40410-014-0015-0

Cite this article as: Mela: Urban public space between fragmentation, control and conflict. City, Territory and Architecture 2014 1:15.

\section{Submit your manuscript to a SpringerOpen ${ }^{\circ}$ journal and benefit from:}

- Convenient online submission

- Rigorous peer review

- Immediate publication on acceptance

- Open access: articles freely available online

- High visibility within the field

- Retaining the copyright to your article

Submit your next manuscript at $\gg$ springeropen.com 